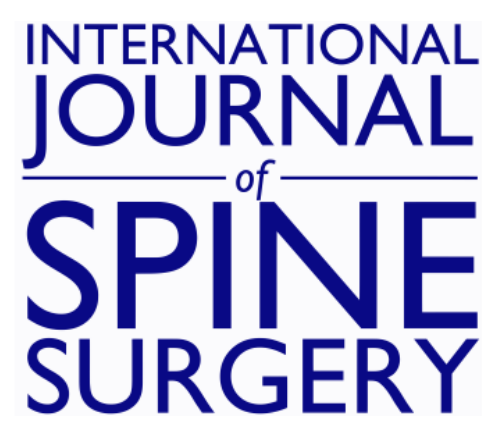

\title{
Transforaminal Endoscopic Discectomy Combined With an Interspinous Process Distraction System for Spinal Stenosis
}

Carolina Ramírez Martínez, Kai-Uwe Lewandrowski, José Gabriel Rugeles Ortíz, Gabriel Oswaldo Alonso Cuéllar and Jorge Felipe Ramírez León

Int J Spine Surg 2020, 14 (s3) S4-S12

doi: https://doi.org/10.14444/7121

http://ijssurgery.com/content/14/s3/S4

This information is current as of April 25, 2023.

Email Alerts Receive free email-alerts when new articles cite this article. Sign up at:

http://ijssurgery.com/alerts

The International Journal of Spine Surgery

2397 Waterbury Circle, Suite 1,

Aurora, IL 60504, Phone: +1-630-375-1432 


\title{
Transforaminal Endoscopic Discectomy Combined With an Interspinous Process Distraction System for Spinal Stenosis
}

\author{
CAROLINA RAMÍREZ MARTÍNEZ, MD, ${ }^{1,2}$ KAI-UWE LEWANDROWSKI, MD, ${ }^{3,4}$ JOSÉ GABRIEL \\ RUGELES ORTÍZ, MD, ${ }^{1,2,3}$ GABRIEL OSWALDO ALONSO CUÉLLAR, DVM, MSC, ${ }^{1,2,3}$ JORGE FELIPE \\ RAMÍREZ LEÓN, MD ${ }^{1,2,3}$ \\ ${ }^{1}$ Centro de Columna-Cirugía Mínima Invasiva, Bogotá, Colombia, ${ }^{2}$ Clínica Reina Sofia-Clinica Colsanitas, Bogotá, Colombia, ${ }^{3}$ Fundación Universitaria Sanitas, \\ Bogotá, Colombia, ${ }^{4}$ Center for Advanced Spine Care of Southern Arizona, Surgical Institute of Tucson, Tucson, Arizona
}

\begin{abstract}
Background: The combination of the percutaneous transforaminal endoscopic decompression (PTED) with an interspinous process distraction system (IPS) may offer additional benefit in the treatment of spinal stenosis in patients who have failed nonsurgical treatment.

Methods: We retrospectively reviewed the medical records of 33 patients diagnosed with lumbar stenosis and radiculopathy and treated them with transforaminal endoscopic lumbar decompression between 2013 and 2017. Primary outcome measures were modified Macnab as well as preoperative and postoperative visual analog scale (VAS) criteria and the Oswestry Disability Index (ODI). Only patients with a minimum follow-up of 2 years were included.

Results: A total of 28 patients were treated with a combination of PTED and percutaneous IPS (group A), and 5 patients were treated with PTED and mini-open IPS (group B). In group A patients, there was a 4.48 reduction in the VAS score. The ODI changed from 50.25 preoperatively to 18.2 postoperatively, and excellent and good Macnab outcomes were obtained in $78 \%$ of patients. In group B patients, the mean VAS reduction was 5.2 points. The ODI changed from 44.34 preoperatively to 14.62 postoperatively, and $80 \%$ of group B patients achieved excellent and good Macnab outcomes. No complications related to PTED or IPS were observed throughout the 2-year follow-up.

Conclusions: The addition of IPS to the PTED procedure in select patients may offer additional benefits to patients being treated for lumbar lateral stenosis and foraminal stenosis with low-grade spondylolisthesis.

Level of Evidence: 3.

Clinical Relevance: Feasibility study.
\end{abstract}

Special Issue

Keywords: lumbar lateral recess and foraminal stenosis, endoscopic spine surgery, interspinous process distraction

\section{INTRODUCTION}

Population growth and increased longevity have created significant challenges in spine care. Lumbar spinal stenosis (LSS) occurs at a high incidence. ${ }^{1}$ Symptoms of LSS are numerous, including radiculopathy and low back pain with neurogenic claudication, and commonly occur in patients over 50 years old. ${ }^{2}$ Management options for LSS include nonsurgical therapy including epidural steroid injections, minimally invasive spine surgery, percutaneous endoscopic lumbar discectomy (PTED), and conventional open decompressive surgery. ${ }^{2}$ Although the "gold standard" operation for LLS is open decompression by laminectomy, it can be associated with increased complications, especially in elderly patients with significant comorbidities. ${ }^{2}$

Interspinous process distraction systems (IPSs) have been developed to treat patients in this category, with simplified small-incision lumbar procedures addressing the claudication symptoms by implanting IPSs under regional anesthesia in combination with local anesthesia. The treating principle behind IPSs is simple: achieve segmental distraction and volumetric increase of the stenotic lumbar lateral recess or foraminal space by placing the device between 2 adjacent spinous processes. ${ }^{1}$ For LSS, IPS has been used to aid in lumbar intervertebral disc height restoration and to increase spinal canal volume at the symptomatic level by decreasing mechanical compression of neural ele- 



Figure 1. The 2 types of IPS are shown: (Left) Cylindrical IPS that was implanted percutaneously. (Right) Wallis-type modular IPS consisting of 2 winglets that are placed and assembled between 2 adjacent spinous processes through a mini-open approach. The integrated Dacron band was used to stabilize the IPS and maintain a constant distraction, producing the indirect decompression effect at the symptomatic claudication level, and thus, stabilizing the symptomatic unstable lumbar motion segment in extension and flexion. IPS, interspinous process distraction system.

ments via indirect decompression while maintaining segmental stability. One example of these firstgeneration stabilizing devices is the Wallis IPS system introduced by Sénégas, which limits both hyperextension and flexion due to the simultaneous tightening of Dacron and maintains a constant grade of distraction. ${ }^{5}$ Second- and third-generation devices have been developed on the basis of this basic IPS concept and are now commercially available. ${ }^{4}$ Their routine clinical use varies from country to country, depending on the medical necessity and benefit-coverage guidelines implemented by the local health insurance system.

Currently, the debate about the appropriate clinical use of IPSs and the best clinical indications in the elderly continues. ${ }^{6-12}$ There is good evidence supportive of the use of IPS for simplified spine care in elderly people suffering from the sciatica-type back and leg pain with some studies showing excellent outcomes in more than $80 \%$ of treated patients. ${ }^{13}$ Conversely, some studies report relatively high reoperation rates. ${ }^{2}$ We hypothesized that the advantages of lumbar IPSs can be enhanced and made more reliable with longterm pain relief if combined with additional transforaminal endoscopic decompression, using just regional anesthesia in the outpatient setting.

\section{MATERIALS AND METHODS}

\section{Study Design and Patients Selection Criteria}

We performed a retrospective study on 33 patients treated for symptomatic LSS and concomitant grade 1 or 2 spondylolisthesis between 2013 and 2017 who presented with radiating lumbar pain refractory to medical treatment for at least 6 months. Patients were treated with percutaneous transforaminal endoscopic lumbar discectomy (PTED) in conjunction with 1 of 2
IPS devices and implantation methods. Three patients had a two-level decompression but a single IPS surgery. A cylindrical IPS was placed between 2 adjacent spinous processes in patients with a rigid grade I spondylolisthesis without any discernable anterolateral translational motion on lateral extension-flexion views (Figure 1, left). In patients with the translational and angular grade I or II motion on preoperative lateral extension-flexion views, a Wallistype device was placed through a mini-open incision. This implant consisted of a modular IPS with a Dacron (INVISTA, Kennesaw, GA) tension band designed to maintain a constant distraction between the spinous processes of an overtly unstable lumbar motion segment (Figure 1, right).

\section{Inclusion Exclusion Criteria}

Included in this study were patients with sciaticatype back and leg pain due to bony and soft tissue spinal stenosis in the central canal, lateral recess, and neuroforamina confirmed on advanced crosssectional imaging studies including MRI and computed tomography (CT) and concomitant spondylolisthesis grade I or II on dynamic extensionflexion views. These criteria have been used by several authors. ${ }^{14-16}$ In addition, patients were stratified concerning the type of IPS implant used; this was based on findings on plain film radiography. Patients with rigid grade I spondylolisthesis received a cylindrical distraction implant, and patients with flexion instability with discernable anterolateral or angular motion on forwarding flexion views received a modular IPS implant with Dacron compression band. Exclusion criteria were metastatic disease, isolated axial back pain, an extruded or migrated disc herniation, or spondylolisthesis higher than grade II. These inclusion and exclusion criteria resulted in the percutaneous implantation of the cylindrical IPS in 28 patients and the mini-open implantation of the modular dual winglet IPS in the remaining 5 patients.

\section{Positioning and Access Planning}

All patients were treated with regional anesthesia and outpatient procedure in a prone position on a radiolucent operating room table equipped with an Andrews frame. Patients were positioned with their hips and knees flexed at $90^{\circ}$. In the posterior-anterior plane, a sagittal midline along the spinous processes was drawn using a guide wire. The surgical intervertebral level was also marked by drawing a 


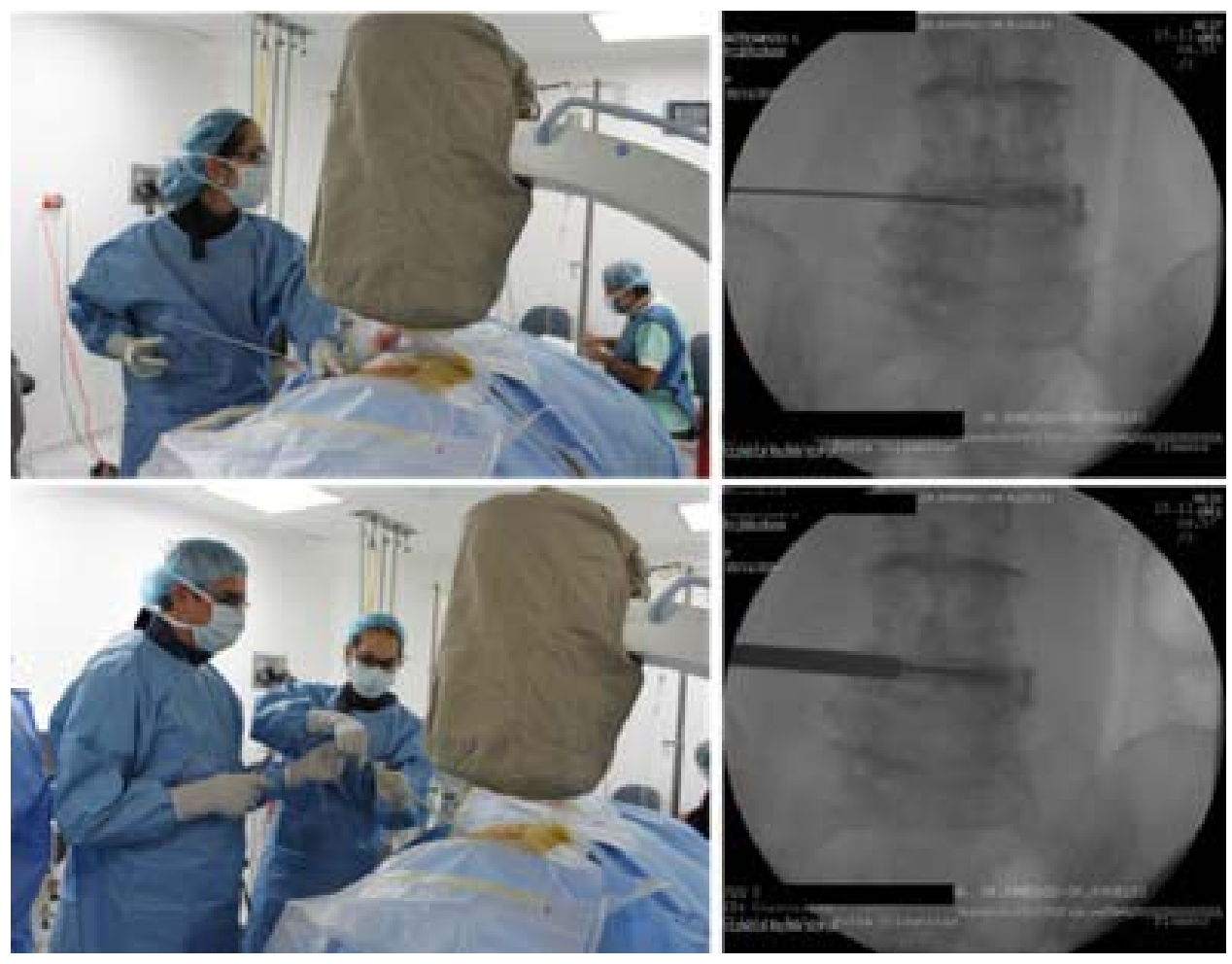

Figure 2. Side-by-side demonstration of surgical steps (left panel) and fluoroscopic view (right panel) of guide wire (top panel) and dilator (bottom panel) placement at L4-L5 after the endoscopic discectomy had been completed at L3-L4 and L4-L5. The fluoroscopic images show residual radiographic dye (Isovue-300) at the L3-L4 and L4-L5 levels in a patient who underwent 2-level endoscopic decompression but single-level concomitant percutaneous placement of a cylindrical IPS. We routinely injected indigo carmine (diluted 1:10) mixed with ISOvue-300 for intraoperative chromodiscography to aid in the removal of herniated disc tissue. IPS, interspinous process distraction system.

perpendicular line centered between the inferior and superior endplates of the vertebral body above and below, respectively. In the lateral plane, the entry point for the transforaminal endoscopic decompression procedure was also marked by lining up the guide wire parallel to the intervertebral space, centering its tip at the posterior annulus. These 2 lines marked the skin entry point for the endoscopic working cannula, typically at a distance between 8 and $12 \mathrm{~cm}$ from the midline. A spinal needle was then directed into the middle one third of the annulus.

\section{Endoscopic Decompression}

The endoscopic working channel was placed over the guide wire after serial dilation into the safe zone, defined as the Kambin triangle. ${ }^{17-20}$ We routinely performed bony and soft tissue removal and injected indigo carmine (diluted 1:10) mixed with Isovue-300 (Bracco Diagnostics, Milan, Italy) for intraoperative chromodiscography to aid in the removal of disc tissue. $^{21}$ The details of the outside-in endoscopic decompression have been published elsewhere. ${ }^{22-25}$ We used the Vertebris Endoscopic System (RIWOspine, GmbH, Knittlingen, Germany). Whenever needed, the discectomy was facilitated by performing a foraminoplasty with trephines, motorized burrs, and Kerrison rongeurs. Once complete access to the herniated disc was achieved, the decompression was completed with forceps and radiofrequency. The Elliquence Trigger Flex Radiofrequency System (Elliquence LLC, Baldwin, NY) was used for thermal annuloplasty and nucleoplasty in an attempt to further complete the discectomy by shrinking frayed annular and disc tissue.

\section{Percutaneous IPS Placement}

The cylindrical IPS was deployed between the adjacent superior and inferior spinous processes of the surgical level using the same posterolateral skin incision and access portal. It was procured from a local company of orthopedic devices (Ortomac SA, Bogotá, Colombia). Under fluoroscopic guidance, a guide wire was passed into the interspinous space, which was then bluntly dissected with serial dilators and sizers. This instrument set provided with the implant was used to establish the appropriate implant size (Figure 2). Typically, the surgeon authors (C.R.M., G.R.O., J.F.R.) deployed an 

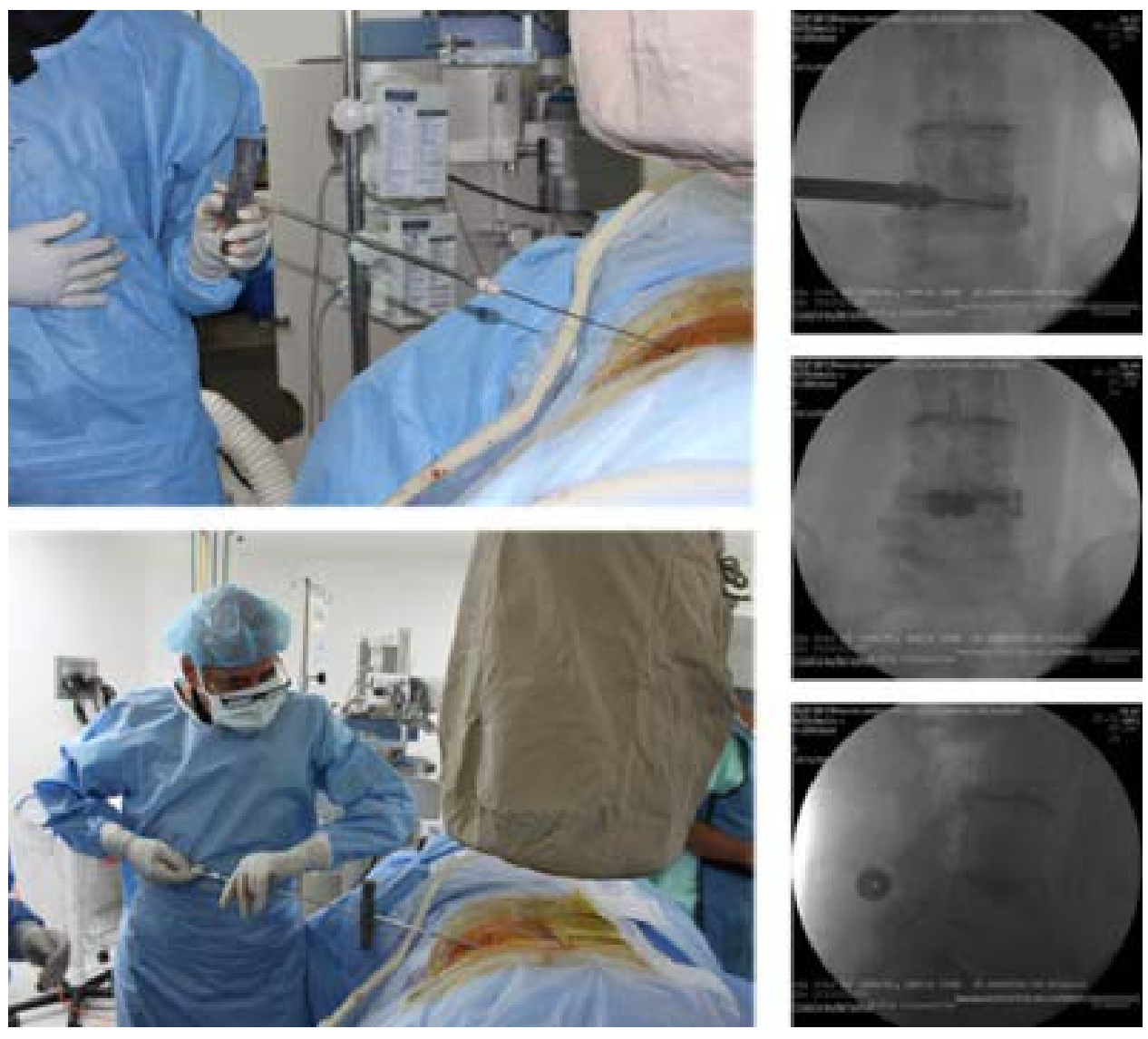

Figure 3. Side-by-side demonstration of surgical steps (left panel) and fluoroscopic view (right panel) of the introduction of the IPS into the interspinous space over the guide wire (top panel) and final deployment (bottom panels). Final implant position is checked intraoperatively in the posteroanterior and lateral fluoroscopic views prior to closing the wound. IPS, interspinous process distraction system.

implant from 9 to $14 \mathrm{~mm}$ in size measured at the center portion of the implant. To achieve a snug fit, the final implant size was chosen by oversizing the implant $1 \mathrm{~mm}$ larger than the last dilator that could just barely be passed between the 2 adjacent spinous processes. The IPS placement was finalized by gently turning it into the interspinous space under fluoroscopic image intensification in the posteroanterior and lateral plane to avoid postsurgical migration (Figure 3). A representative case with percutaneous placement of a cylindrical IPS at the L5-S1 level is shown in Figures 4 and 5.

\section{Mini-Open IPS Placement}

After fluoroscopic verification of the surgical level, the posterior elements were exposed through a less than 4-cm midline after gentle dissection of the paraspinal muscles without periosteal stripping, disruption of the multifidus attachments, or violation of the facet-joint capsule. Then, the interspinous ligament spanning the 2 adjacent spinous processes was resected to assess the maximum distraction possible to size the IPS implant. After implantation of the 2 opposing IPS winglets, the implant was assembled in the midline and stabilized by introducing and tightening a Dacron band around the 2 spinous processes at the surgical level (Figure 6). The final implant position was verified (Figure 7). A representative case is shown in Figure 8.

\section{Clinical Outcomes Evaluation \& Statistical Analysis}

The preoperative baseline and postoperative functioning data were recorded for all patients by using a visual analog scale (VAS) for leg pain, ${ }^{26}$ the Oswestry Disability Index (ODI) score, ${ }^{27-29}$ and the modified Macnab criteria. ${ }^{30}$ The descriptive statistics (mean and standard deviation), cross-tabulation statistics, and measures of association computed for 2-way tables using SPSS Statistics software, Version 26.0 (IBM Corp, Armonk, NY) were based on 2year follow-up data. The Pearson $\chi^{2}$ and the likelihood-ratio $\chi^{2}$ tests were used as statistical measures of association. For the detailed outcome 

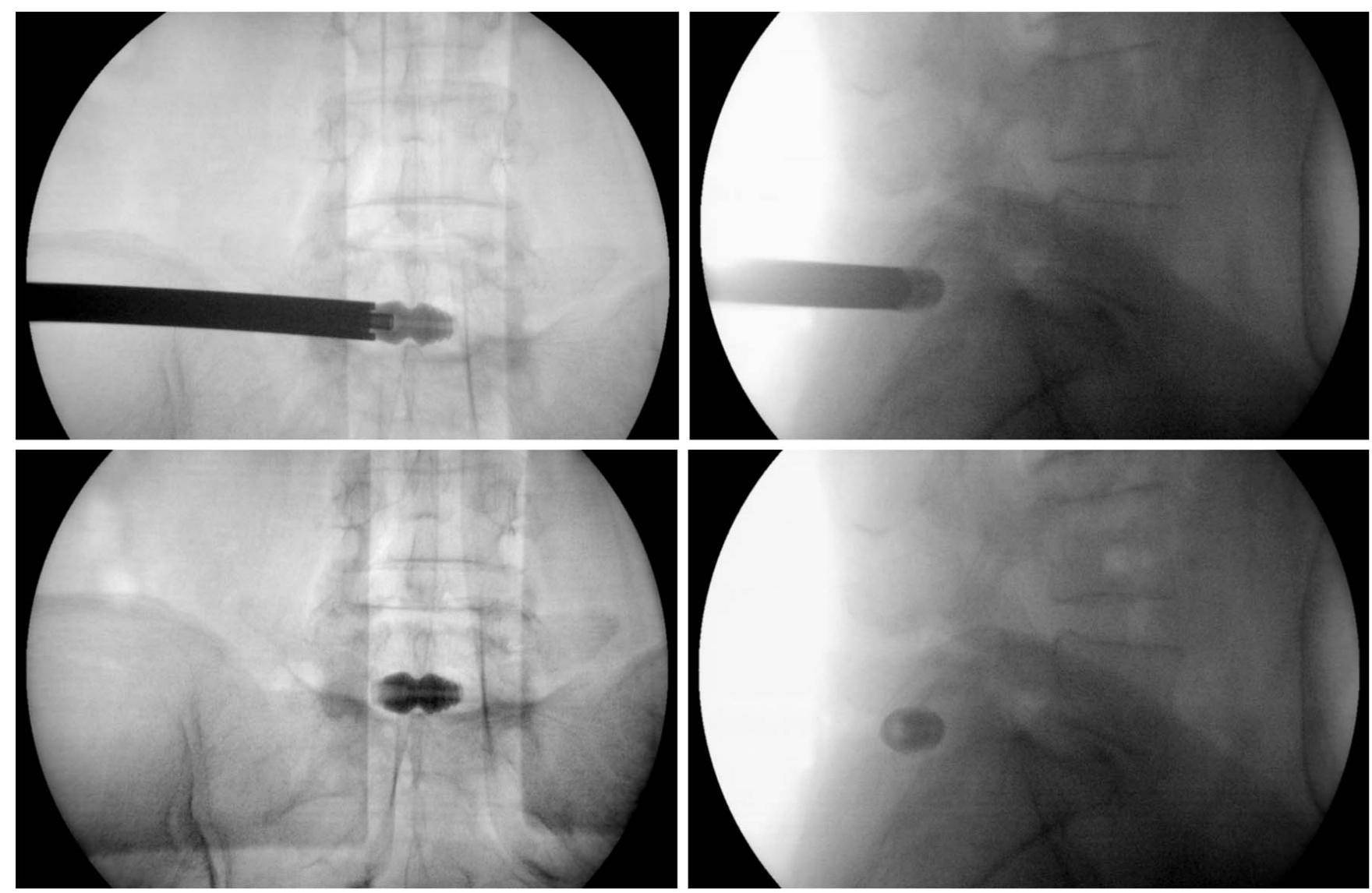

Figure 4. Representative intraoperative posteroanterior and lateral projections (top panels) taken during percutaneous endoscopic transforaminal decompression and stabilization by percutaneous placement of a cylindrical IPS placed between the spinous processes of the symptomatic L5-S1 level. Postoperative images are shown in the bottom 2 panels. IPS, interspinous process distraction system.

analysis, a 2-tailed $t$ test, analysis of variance testing, and cross-tabulation statistics and measures of association were computed for 2-way tables using IBM SPSS Statistics software, Version 26.0. Descriptive statistic measures were used to calculate the mean, range, and standard deviation as well as percentage. Cross-tabulation methods were used to assess for any statistically significant association between stenosis type and clinical outcome data. Pearson $\chi^{2}$ and Fisher exact test were used as statistical measures of association. Expected cell counts, continuity corrections, and likelihood ratios were calculated for some analyses.

\section{RESULTS}

There was a total of 33 study patients. The sample consisted of 19 men $(55 \%)$ and 14 women $(45 \%)$ with an average age of 58.6 years (range, 30 to 91 years; $\mathrm{SD}=16.57$ years), who underwent operations on 36 lumbar levels. The most treated lumbar level was L4-L5 ( $\mathrm{n}=20)$, followed by L5-S1 $(n=9)$, L2-L3 $(n=5)$, and L3-L4 $(n=2)$. For the 28 patients who received the percutaneous cylindrical IPS, the clinical outcome analysis at a minimum 2year follow-up showed a significant reduction $(P$ $<.001$ ) of 4.48 points for the VAS for leg pain, from $8.60(\mathrm{SD}=1.619)$ preoperatively to $4.12(\mathrm{SD}=$ 3.169). The average ODI reduction was 34.99 , from $50.25(\mathrm{SD}=15.26)$ preoperatively to $18.2(\mathrm{SD}=$ 16.47) postoperatively, which was also statistically significant $(P<.001)$. Macnab outcome analysis showed high satisfaction with the combined PTED IPS procedure. Excellent and good Macnab outcomes were obtained in $78 \%$ of patients, with a total of $81 \%$ reporting improvement of pain symptoms if the fair outcomes were included. Six patients with multi-level degenerative disc disease reported poor Macnab outcomes and required additional surgery at the index and other adjacent levels. There was no infection, dural tear, vascular injury, or any other intraoperative or postoperative complication.

In the 5 patients who received the mini-open double winglet IPS with Dacron stabilization between the 2 adjacent spinous processes, the 



Figure 5. Preoperative posteroanterior and lateral projections (left panels) of an 85-year-old woman with claudication symptoms who underwent 2-level percutaneous endoscopic transforaminal decompression and stabilization by percutaneous placement of a cylindrical IPS placed between the spinous processes of the symptomatic L4-L5 and L5-S1 levels with good Macnab outcome at final follow-up. Two-year postoperative images are shown in the right top panels. The standing forward-flexion radiograph in the right bottom panel shows no instability. IPS, interspinous process distraction system.

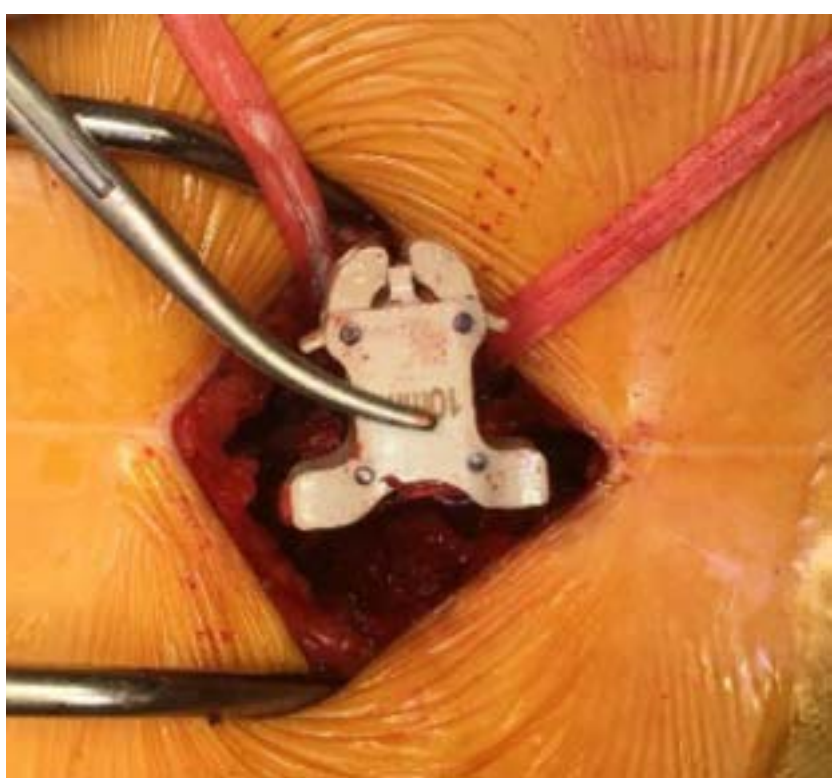

Figure 6. After implantation of the 2 opposing IPS winglets, the implant is assembled in the midline and stabilized by introducing and tightening a Dacron band around the 2 spinous processes at the surgical level. IPS, interspinous process distraction system. clinical outcome analysis at a minimum 2-year follow-up showed a significant reduction $(P<$ $.001)$ of 5.2 points in the VAS for leg pain, from $9.0(\mathrm{SD}=0.707)$ preoperatively to $3.8(\mathrm{SD}=3.563)$. The average ODI reduction was 29.72 , from 44.34 $(\mathrm{SD}=3.563)$ preoperatively to $14.62(\mathrm{SD}=6.976)$ postoperatively, which was also statistically significant $(P<.001)$. Macnab outcome analysis showed high satisfaction with the combined PTED IPS procedure. Excellent and good Macnab outcomes were also obtained in $80 \%$ of patients, with all 5 patients reporting improvement of pain symptoms. There were also no complications in this group of patients.

\section{DISCUSSION}

$L S S$ is defined as a spinal canal narrowing by bone and soft tissues. This pathology is highly related to aging and with degenerative changes in facet joints, ligamentum flavum, posterior longitu- 

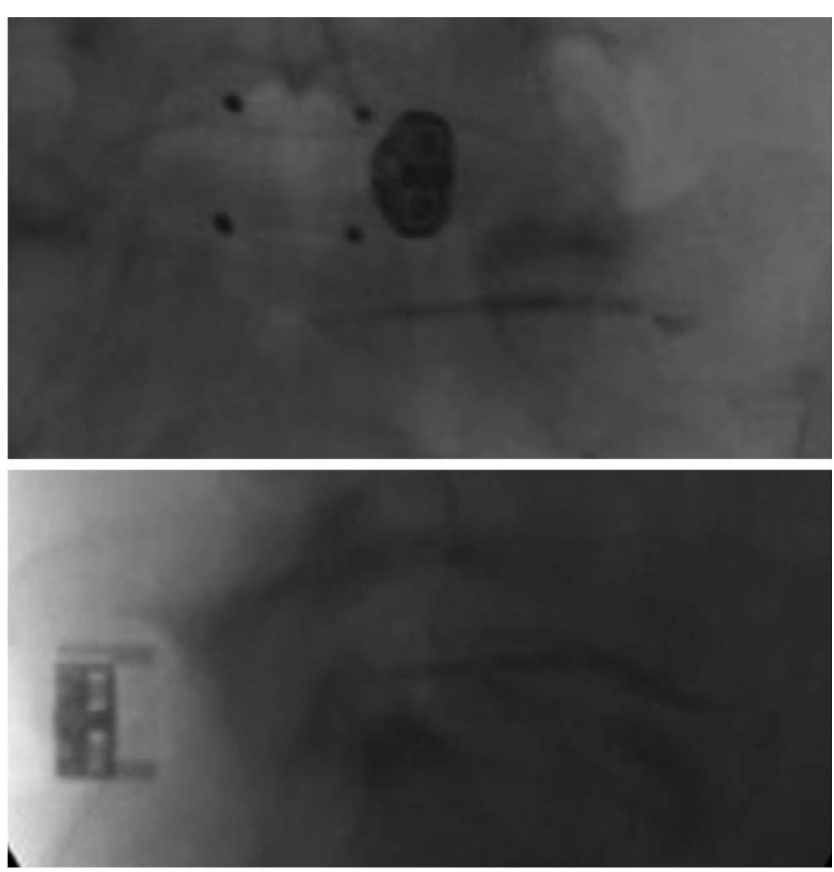

Figure 7. Representative intraoperative posteroanterior and lateral projections are shown routinely used to verify the final IPS position. In this case, a 62-yearold patient suffering from sciatica-type back and leg claudication symptoms due to spondylolisthesis with associated foraminal stenosis underwent percutaneous endoscopic transforaminal foraminotomy and discectomy and stabilization by mini-open placement of a modular IPS placed between the spinous processes of the symptomatic L5-S1 level. IPS, interspinous process distraction system.

dinal ligament, and intervertebral disc. More than $80 \%$ of patients with LSS present with symptoms of radicular pain. ${ }^{2}$ It is clear that although degenerative diseases of the spine (eg, disc disease, stenosis, facet arthrosis) do not have high mortality rates, they may generate significant discomfort and lower quality of life. For the health care system, they create extra costs related to the high number of patients who need to undergo surgical treatment. Current evidence shows that when nonsurgical care with medical and interventional treatment has failed, surgery is the best alternative. ${ }^{31,32}$ Surgical care may be focused by limiting the operation to pain generators that have been validated preoperatively. This selective and staged management approach with endoscopic lumbar decompression proposed by Yeung et $\mathrm{al}^{33}$ has been demonstrated to be reliable and cost-effective. Another recent study ${ }^{34}$ showed that the interspinous distraction systems are also a reasonable, cost-effective alternative for open LSS treatment.

The outcomes of the current feasibility study of performing PTED in conjunction with simultaneous IPS implantation at the same surgical level suggest that there may be merit to further studying the individual contributions from either the endoscopic decompression or the stabilizing and distracting effect of the IPS. The assumption is that clinical outcomes were improved as a result of the combination of these 2 procedures. At a minimum, this argument is not contradicted by the lack of any significant implant-related problems, such as dislocation or migration of the IPS device within the minimum 2-year follow-up period. Conversely, we recognize the limitations of the current study, including the fact that it is a retrospective case series without a control group.

There have been several attempts at adding stabilizing implants to the PTED procedure with the declared goal of making it more reliable. Because patients are searching for minimally invasive outpatient procedures that are less disruptive to their lives, this strategy of broadening the indications of endoscopic surgery with the addition of implants or additional procedural steps to add stability seems intuitive. This combination of PTED with IPS is motivated by the desire to avoid some of common complications associated with decompressive laminectomy alone including failed back syndrome and, ultimately, the need for salvage fusion surgery. This concept needs to be further investigated with a larger, prospective, and controlled study.

The relatively high reoperation rates reported with IPS surgery has been viewed as a weakness of this procedure. ${ }^{35,36}$ A recent systematic review ${ }^{35}$ shows that a common mode of failure of IPSs was the loss of distraction due to erosion of the implant into the adjacent spinous processes or mechanical failure resulting in loosening. The lack of implant failure and reoperation in the present study suggest that there may be an added benefit to combining the PTED with the IPS procedure, perhaps making both methods more reliable. Despite the present study's limitations, we conclude that the addition of IPS to the PTED has merit in select patients. The indications and contraindications need to be studied further in the short- and long-term.

\section{CONCLUSION}

The combination of PTED and interspinous devices in an outpatient setting could be a viable alternative to open LSS management. The low rate of complications suggests that there is limited added risk from combining these 2 procedures when 

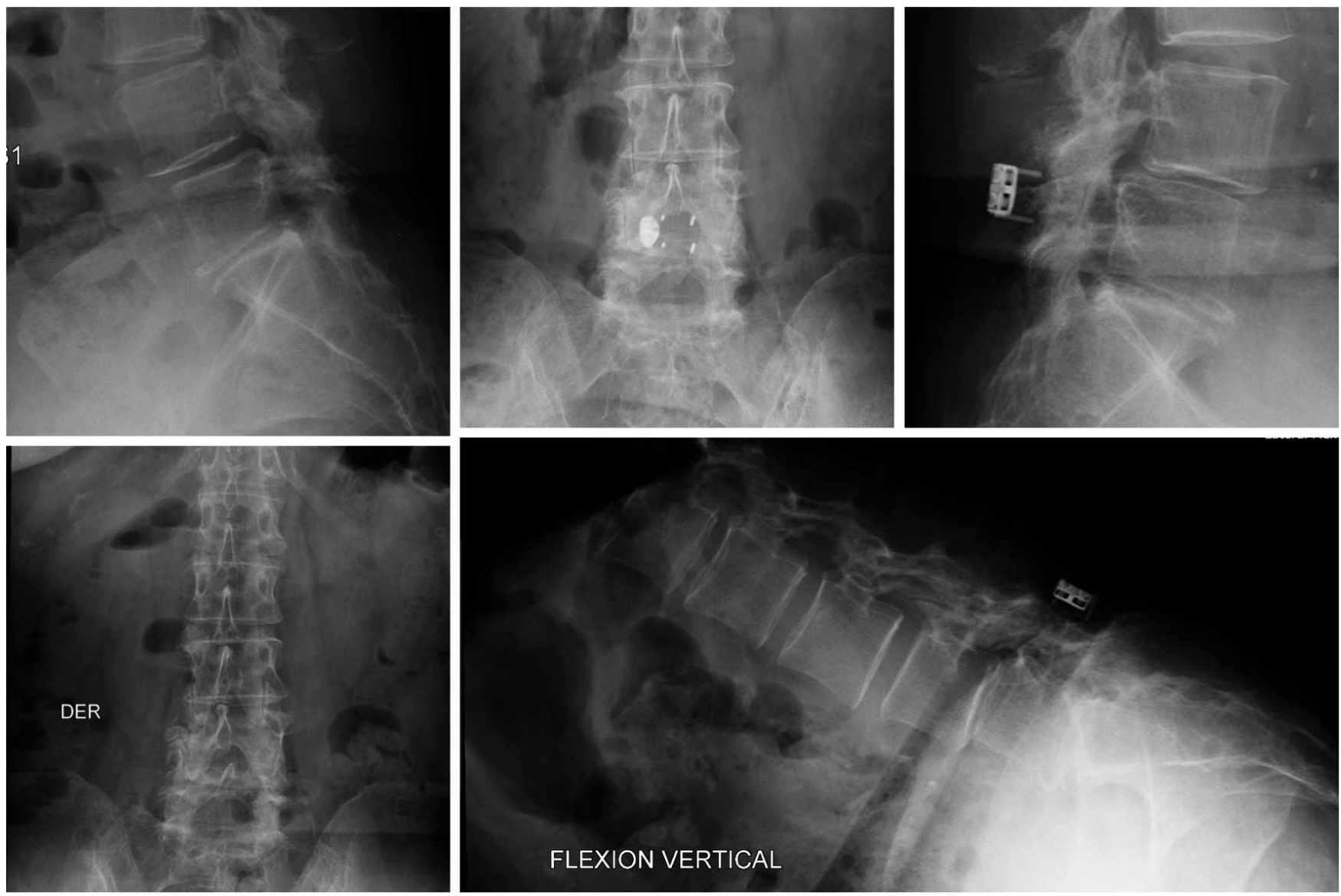

Figure 8. Preoperative posteroanterior and lateral projections (left panels) of an 85-year-old woman with claudication symptoms who underwent 2-level percutaneous endoscopic transforaminal decompression and stabilization by percutaneous placement of a cylindrical IPS placed between the spinous processes of the symptomatic L4-L5 and L5-S1 levels with good Macnab outcome at final follow-up. Two-year postoperative images are shown in the right top panels. The standing forward-flexion radiograph in the right bottom panel shows no instability. IPS, interspinous process distraction system.

performed by surgeons well-trained in each respective technique.

\section{REFERENCES}

1. Phan K, Rao PJ, Ball JR, Mobbs RJ. Interspinous process spacers versus traditional decompression for lumbar spinal stenosis: systematic review and meta-analysis. J Spine Surg. 2016;2(1):31-40.

2. Machado GC, Ferreira PH, Harris IA, et al. Effectiveness of surgery for lumbar spinal stenosis: a systematic review and meta-analysis. PLoS One. 2015;10(3):e0122800.

3. Senegas J. Mechanical supplementation by non-rigid fixation in degenerative intervertebral lumbar segments: the Wallis system. Eur Spine J. 2002;11 Suppl 2:S164-169.

4. Bono CM, Vaccaro AR. Interspinous process devices in the lumbar spine. J Spinal Disord Tech. 2007;20(3):255-261.

5. Alfieri A, Gazzeri R, Prell J, et al. Role of lumbar interspinous distraction on the neural elements. Neurosurg Rev. 2012;35(4):477-484; discussion 484.

6. Galarza M, Gazzeri R, De la Rosa P, Martinez-Lage JF. Microdiscectomy with and without insertion of interspinous device for herniated disc at the L5-S1 level. J Clin Neurosci. 2014;21(11):1934-1939.

7. Gazzeri R, Galarza M, Alfieri A. Controversies about interspinous process devices in the treatment of degenerative lumbar spine diseases: past, present, and future. Biomed Res Int. 2014;2014:975052.

8. Gazzeri R, Galarza M, Alfieri A. Response to: Comment on "Controversies about Interspinous Process Devices in the Treatment of Degenerative Lumbar Spine Diseases: Past, Present, and Future". Biomed Res Int. 2017;2017:1504316.

9. Gazzeri R, Galarza M, Neroni M, et al. Failure rates and complications of interspinous process decompression devices: a European multicenter study. Neurosurg Focus. 2015;39(4):E14.

10. Neroni M, Gazzeri R, Conforti G, Visocchi M. State of art of recurrent lumbar disk herniation, interspinous and interlumbar fusions. J Neurosurg Sci. 2014;58(2 Suppl 1):45-48.

11. Puzzilli F, Gazzeri R, Galarza M, et al. Interspinous spacer decompression (X-STOP) for lumbar spinal stenosis and degenerative disk disease: a multicenter study with a minimum 3-year follow-up. Clin Neurol Neurosurg. 2014;124:166-174.

12. Laratta JL, Reddy H, Lombardi JM, et al. Utilization of Interspinous Devices Throughout the United States Over a 
Recent Decade: An Analysis of the Nationwide Inpatient Sample. Global Spine J. 2018;8(4):382-387.

13. Lewandrowski K-U, Ransom NA. Five-year clinical outcomes with endoscopic transforaminal outside-in foraminoplasty techniques for symptomatic degenerative conditions of the lumbar spine. Journal of Spine Surgery. 2019:S54-S65.

14. Yeung A, Lewandrowski K-U. Five-year clinical outcomes with endoscopic transforaminal foraminoplasty for symptomatic degenerative conditions of the lumbar spine: a comparative study of inside-out versus outside-in techniques. Journal of Spine Surgery. 2019:S66-S83.

15. Yeung A, Roberts A, Zhu L, Qi L, Zhang J, Lewandrowski KU. Treatment of Soft Tissue and Bony Spinal Stenosis by a Visualized Endoscopic Transforaminal Technique Under Local Anesthesia. Neurospine. 2019;16(1):52-62.

16. Kambin P, Sampson S. Posterolateral percutaneous suction-excision of herniated lumbar intervertebral discs. Report of interim results. Clin Orthop Relat Res. 1986(207):37-43.

17. Kambin P, Brager MD. Percutaneous posterolateral discectomy. Anatomy and mechanism. Clin Orthop Relat Res. 1987(223):145-154.

18. Kambin P, Schaffer JL. Percutaneous lumbar discectomy. Review of 100 patients and current practice. Clin Orthop Relat Res. 1989(238):24-34.

19. Schaffer JL, Kambin P. Percutaneous posterolateral lumbar discectomy and decompression with a 6.9-millimeter cannula. Analysis of operative failures and complications. $J$ Bone Joint Surg Am. 1991;73(6):822-831.

20. Bini W, Yeung AT, Calatayud V, Chaaban A, Seferlis T. The role of provocative discography in minimally invasive selective endoscopic discectomy. Neurocirugia (Astur). 2002;13(1):27-31; discussion 32.

21. Hoogland T, van den Brekel-Dijkstra K, Schubert M, Miklitz B. Endoscopic transforaminal discectomy for recurrent lumbar disc herniation: a prospective, cohort evaluation of 262 consecutive cases. Spine (Phila Pa 1976). 2008;33(9):973-978.

22. Hoogland T, Schubert M, Miklitz B, Ramirez A. Transforaminal posterolateral endoscopic discectomy with or without the combination of a low-dose chymopapain: a prospective randomized study in 280 consecutive cases. Spine (Phila Pa 1976). 2006;31(24):E890-897.

23. Schubert M, Hoogland T. Endoscopic transforaminal nucleotomy with foraminoplasty for lumbar disk herniation. Oper Orthop Traumatol. 2005;17(6):641-661.

24. Hoogland T. Percutaneous endoscopic discectomy. $J$ Neurosurg. 1993;79(6):967-968.

25. Reed CC, Wolf WA, Cotton CC, Dellon ES. A visual analogue scale and a Likert scale are simple and responsive tools for assessing dysphagia in eosinophilic oesophagitis. Aliment Pharmacol Ther. 2017;45(11):1443-1448.

26. Fairbank J. Use of Oswestry Disability Index (ODI). Spine (Phila Pa 1976). 1995;20(13):1535-1537.

27. van Hooff ML, Mannion AF, Staub LP, Ostelo RW, Fairbank JC. Determination of the Oswestry Disability Index score equivalent to a "satisfactory symptom state" in patients undergoing surgery for degenerative disorders of the lumbar spine-a Spine Tango registry-based study. Spine J. 2016;16(10):1221-1230.

28. van Hooff ML, Spruit M, Fairbank JC, van Limbeek J, Jacobs WC. The Oswestry Disability Index (version 2.1a): validation of a Dutch language version. Spine (Phila Pa 1976). 2015;40(2):E83-90.

29. Macnab I. The surgery of lumbar disc degeneration. Surg Аппи. 1976;8:447-480.

30. Aalto TJ, Malmivaara A, Kovacs F, et al. Preoperative predictors for postoperative clinical outcome in lumbar spinal stenosis: systematic review. Spine (Phila Pa 1976). 2006;31(18):E648-663.

31. Kovacs FM, Urrutia G, Alarcon JD. Surgery versus conservative treatment for symptomatic lumbar spinal stenosis: a systematic review of randomized controlled trials. Spine (Phila Pa 1976). 2011;36(20):E1335-1351.

32. Yeung A, Lewandrowski K-U. Early and staged endoscopic management of common pain generators in the spine. Journal of Spine Surgery. 2019:S1-S5.

33. Tapp SJ, Martin BI, Tosteson TD, et al. Understanding the value of minimally invasive procedures for the treatment of lumbar spinal stenosis: the case of interspinous spacer devices. Spine J. 2018;18(4):584-592.

34. Epstein NE. A review of interspinous fusion devices: High complication, reoperation rates, and costs with poor outcomes. Surg Neurol Int. 2012;3:7.

35. Smith ZA. Interspinous process device versus standard conventional surgical decompression for lumbar spinal stenosis results in increased reoperation rates and costs without improving patient outcomes. Evid Based Med. 2014;19(4):136.

Disclosures and COI: The views expressed in this article represent those of the authors and no other entity or organization. The authors are accountable for all aspects of the work in ensuring that questions related to the accuracy or integrity of any part of the work are appropriately investigated and resolved. This article is not meant for or intended to endorse any products or push any agenda other than the associated clinical outcomes with endoscopic spine surgery. The motive for compiling this clinically relevant information is by no means created and/or correlated to directly enrich anyone due to its publication. This publication was intended to substantiate contemporary endoscopic spinal surgery concepts to facilitate technology advancements. The senior author (J.F.R.) and his team of coauthors designed and marketed the interspinous process spacers and receive royalties and distributions from the sale of their product by Ortomac. Additional indirect conflicts of interest may exist due to honoraria, consultancies to other vendors, and companies including Elliquence, LLC. The second author (K.U.L.) has no direct or indirect conflicts of interest.

Corresponding Author: Kai-Uwe Lewandrowski, MD, Center for Advanced Spine Care of Southern Arizona, Surgical Institute of Tucson, 
Tucson, Arizona. Phone: (520) 204-1495; Email: charge by ISASS, the International Society for the business@tucsonspine.com.

Advancement of Spine Surgery. Copyright (C) 2020

Published 9 December 2020

ISASS. To see more or order reprints or permis-

This manuscript is generously published free of sions, see http://ijssurgery.com. 